\title{
Los procesos vinculares de colonización emocional en una pareja
}

\section{Bonding processes of emotional colonization in a couple}

\author{
José Antonio Méndez Ruiz \\ Sociedad Forum de Psicoterapia Psicoanalítica, España
}

\begin{abstract}
Resumen: La colonización emocional, tal y como es descrita por Hugo Bleichmar, es un proceso psicológico intersubjetivo por el cual alguien pasa a pensar, sentir y actuar bajo la influencia de otro, el colonizador, el cual le impone su subjetividad sin que el colonizado tenga conciencia de ello, viviendo su estado como si fuera propio y no inoculado por el otro. Mediante el estudio detallado de las primeras fases de un caso clínico de colonización emocional en la pareja, se quiere mostrar el carácter fundamentalmente vincular del fenómeno, cuyo resultado final proviene de la interacción de las propias necesidades y angustias de cada uno de los miembros, definidas desde el enfoque modular-transformacional. También se destaca cómo el colonizador puede ser, a su vez, colonizado en otras áreas o relaciones de su vida. Se sugieren diversas fases terapéuticas para poner en marcha el proceso de descolonización emocional.
\end{abstract}

Palabras clave: colonización emocional, enfoque modular-transformacional, tratamiento en fases, vinculo terapéutico, vínculo interpersonal.

\begin{abstract}
Emotional colonization is an intersubjective psychological process by which someone thinks, feels and acts under the influence of another, the colonizer, which imposes its subjectivity without the awareness of the colonized person, living his state as if it were his own and not inoculated by the other. The detailed study of the early phases of a clinical case of emotional colonization in the couple seeks to show the fundamentally relational character of the phenomenon. The final result of the process comes from the interaction of the needs and anxieties of each of the members, as defined in the modular-transformational approach. It is also emphasized how the colonizer can be, in turn, colonized in other areas or relationships of his life. Different therapeutic phases to start-up the process of emotional decolonization are suggested.

Keywords: emotional colonization, modular-transformational approach, treatment in phases, therapeutic bond, interpersonal bond.
\end{abstract}

La correspondencia sobre este artículo debe enviarse al autor al e-mail: j.a.mendezruiz@gmail.com

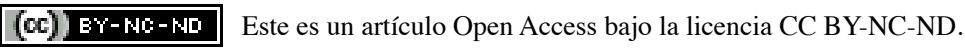


El fenómeno de la colonización emocional, descrito por Hugo Bleichmar (http://www.colonizacionemocional.com) y expuesto en un artículo aparecido en la revista Aperturas psicoanalíticas (Bleichmar y Espeleta, 2017), señala el proceso psicológico, por mejor decir, el proceso psicológico intersubjetivo por el cual alguien pasa a pensar, sentir y actuar bajo la influencia de otro, el colonizador, que le impone su subjetividad sin que el colonizado tenga conciencia de ello, viviendo por lo tanto su estado como si fuera propio y no inoculado por el otro. A esta primera definición, los autores añaden una importante especificidad de este proceso cuando señalan un tipo de colonización emocional que se produciría "desde dentro"; en estos casos se daría una falta de reflexión por parte del colonizado sobre sus propios pensamientos, sus emociones o los mandatos de su superyó, a los cuales tiene que obedecer para no sentir vergüenza, culpa o experimentar castigos. Es decir, en vez de pensar, "es pensado" por sus pensamientos, arrastrado por reacciones emocionales automáticas. Los autores finalizan afirmando que ambos tipos de colonización emocional, la externa y la interna, comparten la falta de libertad, la restricción del ser.

Es necesario insistir en que el proceso de la colonización emocional no es un proceso unidireccional, por el contrario, forma parte de una estructura intersubjetiva compleja que incluye modos de sentir y pensar y modos de relación entre ambos participantes, en la que participan ambos y que todo ello condiciona los modos de actuación, particulares en cada caso, ante los acontecimientos que se van produciendo dentro y fuera de la pareja que forman colonizador y colonizado. En este sentido, no podemos olvidar que el proceso de colonización se produce en el seno de un vínculo y lo que entre sus integrantes ocurre debe ser comprendido a partir de dicha interacción vincular. No puede existir un colonizador sin conseguir que un otro haya aceptado, en mayor o menor medida y en buena parte de modo inconsciente, su propuesta vincular, al modo en que plantea el proceso de adjudicación y asunción de roles Pichon-Rivière (1971). El colonizador consigue introducir al colonizado en su universo de significaciones, en sus modos de afrontar la realidad, en definitiva, en sus propuestas vinculares, pero el colonizado, por sus propias razones psicológicas, se introduce ahí y puede llegar a potenciar, por más que la mayor parte de los fenómenos se produzcan en lo inconsciente, los ejes vinculares.

La colonización emocional se sustenta en las necesidades emocionales de cada uno de los intervinientes, por lo que no puede estudiarse considerando tan solo los factores relacionados con el colonizado. Al darse siempre en una estructura relacional, el fenómeno de la colonización emocional se sustenta en las necesidades emocionales de colonizado y colonizador y a él llegan ambos con un bagaje de estructura psíquica intrasubjetiva propia que propicia que se dé ese tipo de encuentro y no otro de los muchos que serían posibles.

En el artículo de Bleichmar y Espeleta antes citado se centra este encuentro en las diferentes necesidades y deseos que se entrecruzan a partir del interjuego de los sistemas motivacionales de ambos, tal y como se conciben dichos sistemas motivacionales desde el enfoque modular-transformacional (Bleichmar, 1997; Méndez Ruiz e Ingelmo Fernández, 2009) Así, la estructura intersubjetiva tiene que ver con satisfacer las diferentes necesidades motivacionales que concurren en colonizador y colonizado (de apego, narcisistas, de regulación psicobiológica, sexuales o auto o heteroconservativas) y que procuran a uno y otro ya sea un bienestar, ya sea un alejamiento de vivencias angustiosas. Por lo tanto, la satisfacción de las necesidades o deseos pertenecientes a los sistemas motivacionales es una de las fuerzas que configuran la estructura intersubjetiva entre colonizador y colonizado. Sin embargo, la complejidad de dicha estructura incluye cualquiera de las dimensiones del psiquismo que consideremos: los modelos de identificación predominantes, con los discursos y/o el aprendizaje procedimental provenientes de los otros; los niveles de activación psicobiológica; los niveles de agresividad; el miedo por ansiedades persecutorias; las capacidades de manejo de la realidad interna y el mundo externo, tendencia a la acción o a la inhibición, etc. Cualquiera de estas dimensiones puede ser fundamental en el origen y mantenimiento de estas situaciones.

\section{Los vínculos de colonización emocional en la pareja}

La colonización emocional en el seno de la pareja, en sus diferentes modalidades, podría ser considerada como el resultado final de un proceso en el cual intervienen múltiples factores, en diferentes proporciones, 
según cada caso específico y en los que acaban siendo determinantes tanto los tipos de vínculo que se han dado en la pareja como lo que cada uno de los miembros trae de su estructura intrapsíquica a la relación.

Quisiera ejemplificar estos fenómenos exponiendo el desarrollo de las primeras etapas de un proceso terapéutico en el que los fenómenos de colonización emocional están en primera línea y en el que podemos ver la complejidad y especificidad de los elementos en juego, así como sugerir diversas fases y tipos de intervención en las primeras fases del tratamiento con el fin de poner en marcha el proceso de descolonización emocional. Para empezar, habría que recalcar, como se menciona en el artículo de Bleichmar y Espeleta (2017) (al que volvemos reiteradamente ya que es el único artículo publicado hasta el momento sobre el tema), que, aunque al hablar de la colonización pensemos casi de un modo automático en un proceso de dominación de una persona sobre otra, es decir, un colonizador que desea de modo explícito y consciente el sometimiento afectivo e intelectual del otro, esto no se da en todos los casos. Por importantes y frecuentes que sean estas situaciones, que lo son, no explican el fenómeno en su totalidad. Las situaciones con que nos encontramos en la clínica son mucho más diversas y la participación de factores inconscientes está en un primer plano. Así, nos encontramos con situaciones en las que el colonizador no desea controlar al otro, hacerle mal o someterlo, por el contrario, puede tratarse de alguien bienintencionado pero débil que llega a colonizar como forma de superar sus propias debilidades y/o miedos o, como veremos más adelante, porque busca colonizar para apoyarse en el otro y sentir una fortaleza que por sí mismo no posee al estar colonizado en otros ámbitos externos a la pareja, en este caso en su familia de origen.

Este caso clínico de colonización emocional que quiero desarrollar ofrece diversas particularidades. Se trata de un proceso de colonización en una pareja que incluye dos características específicas: se produce entre dos "buenas personas", en el sentido de que no hay deseo de dañar; y es una colonización emocional parcial, en un doble sentido: solo se da en un ámbito muy determinado del vínculo y la aceptación del punto de vista del otro solo es completa en momentos emocionales concretos. Es un vínculo en el que se da un intenso proceso de escisión (seguramente inevitable, en mayor o menor medida, en los casos de colonización emocional) y que podemos considerar en diversos sentidos como plantea Blass (2013), es decir, tanto un proceso en el que se niega la realidad de un deseo, en este caso de necesidad de una diferente valoración y apego, como en un sentido disociativo para proteger al objeto y al vínculo. Así, la parte que podemos denominar como colonizada, sabe intelectualmente lo que ocurre, pero ello no le evita la permanente sensación emocional de duda en sus percepciones y sentimientos en momentos de gran intensidad emocional, hasta el punto de abandonar sus propios juicios. Esto es, no puede desengancharse emocionalmente del proceso relacional. Una vez más nos encontramos con el doble registro entre lo racional/cognitivo y lo emocional y, como suele ser la norma, es éste último el que se impone y dirige la vida de la paciente.

En el tratamiento de estos casos nos encontramos en general con estructuras vinculares fuertemente establecidas, por ello, el trabajo de descolonización emocional consiste en la modificación de un relato vivencial sobre sí-mismo y sobre el mundo inoculado desde fuera y aceptado sin reflexión consciente. El trabajo terapéutico es complejo, artesanal y tiene por objeto la sustitución de ese relato, no por el que inocule el terapeuta, sino por la introducción de una capacidad de reflexión, de juicio propio en el paciente. Por supuesto que a lo largo del proceso siempre nos encontraremos con momentos de alta intensidad emocional, que deberán ser atendidos y que precisarán de intervenciones específicas de diverso tipo e interpretaciones desveladoras de sentido, pero este no va a ser el grueso del trabajo terapéutico. El relato que nos trae el paciente se ha desarrollado en los múltiples micro-intercambios repetidos dentro de los vínculos vividos por el paciente, vínculos en muchos casos idealizados. Por lo tanto, el proceso de descolonización emocional deberá pasar por los múltiples micro-intercambios que se producen en el vínculo terapéutico, al modo del abordaje propuesto por el grupo de Boston (2010). Por ello, en la exposición del caso clínico traeré ejemplos de dichos intercambios.

Otro aspecto a tener en cuenta es el del factor transgeneracional en las experiencias de colonización, de modo que siempre debemos considerar la posibilidad de que el colonizador puede llegar a serlo como forma de escapar o mitigar una propia situación de colonización que trae al vínculo. 


\section{Fases del tratamiento e intervenciones psicoterapéuticas}

Mi primer encuentro con la paciente sigue a un episodio dramático de intento de suicidio que está a punto de matarla. Es el marido quien llama pidiendo la cita estando su mujer recuperándose en el hospital. Los primeros meses del tratamiento giran alrededor del intento de suicidio, nos vemos tres veces por semana en este primer tiempo del tratamiento. El miedo entre su familia a que se repita el intento autolítico es muy grande, también las presiones para que se ingrese en un hospital, haga otro tipo de tratamiento, tome más medicación, etc. En este sentido, me parece que lo más conveniente para nuestro trabajo es que yo mismo me haga cargo del tratamiento farmacológico y eso hago.

Encuentro una mujer abatida por lo que ha ocurrido. No por su intento de matarse o su deseo de morir, si no por el daño que siente que ha hecho a su familia:

P. (paciente): No me puedo perdonar el sentir que les he hecho mucho daño. Están destrozados y muy asustados... cuando los he visto así, cómo me abrazaban llorando en el hospital, cómo me decían que por qué lo había hecho... entonces me di cuenta del daño que les había provocado.

T. (terapeuta): ¿Y el riesgo para tu vida?

P.: Eso no me importa, no podía seguir así, por eso pensé que lo mejor era desaparecer.

T.: ¿No contaba, entonces?

P.: Llevaba tiempo pensando que mejor me moría, que así les iría mejor... yo me siento totalmente prescindible, solo le doy problemas y mi marido los tiene por todos lados... si fuera por mí lo volvería a hacer mañana, pero que nadie se preocupe, les he jurado que no lo haré más y pienso cumplirlo [esto lo dice delante de sus hijos y su marido, a solas conmigo lo mantiene].

Con este discurso se mantiene durante semanas. La convicción de que es un estorbo se mantendrá inamovible durante meses. En estas primeras semanas escucho su desgarro interior, en un discurso reiterativo sobre su desesperación y su sentimiento de inutilidad.

Enseguida queda claro que el problema gira alrededor de la relación con su marido o, por ser más exactos, con los conflictos que provoca a la relación entre ellos la que su marido mantiene con su familia de origen. A medida que avanza el tratamiento constato que ella ha estado sumida en un estado de desesperación creciente en el último año y medio, aunque manteniendo un aspecto de normalidad.

El episodio autolítico se va gestando en su cabeza a lo largo de meses y se concretiza tras una fiesta familiar en la que, una vez más, siente el desprecio de su familia política ante la inacción, que ella siente como indiferencia, incluso complicidad, de su marido. Considera entonces que ya no vale la pena seguir luchando, que esto se repite sin fin y empieza a madurar su idea de morir como forma de desaparecer y no ser causante de más problemas.

P.: Él me olvidará pronto y vivirá mucho más feliz... en realidad soy un permanente estorbo para él.

El día anterior al intento autolítico, ante su queja por lo ocurrido, encuentra en su marido lo que considera como respuesta habitual: “¡Exageras las cosas, no son como tú los ves! ¡Déjame que yo me ocupe de las cosas de mi familia!...." En ese momento decide que es mejor morir y pone en marcha el intento.

Esto que antes denominé proceso de colonización emocional parcial introduce a la paciente en una disyuntiva emocional imaginaria que, por más absurdo que pueda parecer desde una observación racional, no le deja más salida que el intento autolítico: no le es posible aguantar los sentimientos de menosprecio de su familia política, no puede soportar que su marido no la defienda y no le permita defenderse a ella misma. Ella está convencida de ser un estorbo para la vida de su marido, pero no le es posible separarse de él.

P.: Cuando me enfado y veo su cara de sufrimiento no lo puedo resistir.

T.: Matarte como única salida... ¿nunca pensaste en separarte?

P.:¿Separarme?, es imposible, no podría vivir sin él, me moriría... además seguro que tiene razón en que lo exagero todo... por eso lo tenía y lo tengo tan claro, mi única salida era quitarme de en medio. Mis ideas son un estorbo.

Lo lanza con la seguridad que da el convencimiento de la lógica de un razonamiento emocional interno. 


\section{Proceso terapéutico}

En primer lugar, no podemos dejar de señalar que todo lo que viene a continuación necesita de una premisa sin la cual nada es posible: la necesidad de construir un vínculo seguro como primer objetivo terapéutico. Es en el seno de éste donde el resto de los procesos van a tener lugar.

Primera fase del tratamiento: búsqueda de la expresión explícita de los datos biográficos. En esta fase inicial, le pido que me vaya dando datos concretos en los que asienta sus sentimientos.

P.: En primer lugar está mi suegra, desde el primer día que me conoció empezaron las miradas y los desprecios, ha sido así todos estos años. No sólo conmigo, también con sus nietos, jamás ha recordado un cumpleaños o hecho un regalo... no más de dos veces se habrá quedado con ellos, y cuando volvíamos siempre era lo mismo: ¡son buenos, pero no paran, han roto cosas, etc!... de mí ha dicho que era como una puta, que vaya forma de vestir o de hablar, lo ha comentado a mis cuñadas. Como era importante para mi marido, durante años me he ocupado de felicitarle, de llevarle a los niños. Incluso les he dado dinero a mis hijos por Navidad diciendo que era de parte de su abuela, para que no rompieran los lazos con ella. En 30 años no nos habrá invitado a comer a su casa más de tres o cuatro veces. Sus comentarios son siempre despreciativos...

Intervengo poco, sólo lo que creo necesario para estimular su relato. Pero trato de que la escucha sea muy cercana, muy empática, evitando grandes silencios por mi parte.

P.: He tapado a mi marido muchas de las cosas que hacía su madre, pero eso no importa mucho porque cuando se lo he ido diciendo su respuesta es que exagero... Además, su madre muestra una actitud extremadamente hipócrita cuando habla con su hijo sobre mí: pregunta por mí, le comenta que está deseando verme... pero desde que yo dejé de llamarle hace unos años nunca me ha llamado, jamás. Yo hace años que dejado de ir a verla... mi suegro era encantador, me llevaba muy bien con él, venía a vernos, ella jamás.

Estas y las que iré refiriendo son una mera selección de decenas de anécdotas en este sentido.

En esta primera fase busco con mis intervenciones obtener información, pero no sólo por los datos en sí, sino porque veo que es la primera vez que ella explicita, pone en palabras este cúmulo de sentimientos frustrantes. Busco que traiga anécdotas tan vivencialmente como sea posible, que ella misma las escuche en presencia de otro. En general procuro intervenir poco para que sea su discurso el que se vaya abriendo paso. En estos primeros momentos trato de ser muy neutro, hasta donde es posible, y evito mostrar explícitamente mis sentimientos u opiniones ante lo que ella va contando, evito señalamientos o interpretaciones sobre su conducta. Me implico activamente en que ella traiga las anécdotas tan vivencialmente como sean posibles, en eso sí soy muy estimulante. Considero que la posibilidad de que la paciente escuche su discurso en presencia de otro, es un proceso que ayuda por sí mismo a que sus ideas y sentimientos sean menos egosintónicos, es decir, ayuda a disminuir paulatinamente la disociación.

Segunda fase del tratamiento: desmantelamiento del relato introyectado. Una vez obtenidos estos datos y en una segunda fase del tratamiento me propongo una actitud más activa buscando ayudar al desmantelamiento del relato introyectado. Le pregunto por el que parece ser el foco de su colonización emocional, es decir, su marido.

P.: Él es muy bueno. En realidad, nuestra relación es estupenda. Hemos viajado por medio mundo, tenemos amigos comunes con los que lo pasamos muy bien. Disfrutamos mucho juntos y casi nunca discutimos.

T.: ¿Es sólo este tema?

P.: ¡Solamente!

T.: Lo dices con mucha seguridad, pero me es difícil creerlo.

P.: Puede ser, pero es así. Él es tímido con su madre, no sabe enfrentarse... él no puede actuar de otra manera. Cuando aparecen estos temas se pone muy triste, entonces yo me siento muy mal, me siento mala. Me doy cuenta de que tiene razón.

Me parece una descripción muy simplificada en la que faltan muchos elementos, pero no comento nada.

A medida que vamos hablando van surgiendo nuevos datos y un llamativo contraste entre la brillante trayectoria personal y profesional de la paciente y el modo tan inhibido y con pocos recursos con que afronta 
estos problemas en la relación con su marido. Me sorprende mucho al escucharlo, en realidad también a ella, aunque es muy curioso observar como esa fuerte contradicción entre dos modos tan diferentes de actuar, no le provoca ninguna pregunta, como si emocionalmente no registrase las diferencias.

P.: ¡No me pasa más que con él!

T.: Tu trabajo es muy delicado, exige negociar, enfrentarse a los otros.

P.: Nunca he tenido problemas para poner límites. Permanentemente tengo que negociar contratos, poner límites a los clientes o ceder cuando es necesario... no quiero darte una imagen exagerada, pero en mi mundo profesional prefieren no tener que negociar conmigo. Creo que soy muy estimada y respetada y así me siento. Yo he sido toda mi vida una luchadora, nunca tuve temor de enfrentarme con los problemas.

T.: ¿Y con los amigos?

P.: Bueno, yo no soy discutidora, me suelo llevar bien con todo el mundo, pero desde luego no dejo que me impongan lo que tengo que hacer y creo que nunca me he callado una opinión que me parecía importante... [Verbal y corporalmente muestro mi sorpresa]... Sí, lo estoy diciendo ahora y parece mentira, pero es así, sólo me pasa en este asunto.

Insisto en centrar el foco en su marido.

P.: Él es muy bueno, en realidad es una víctima y no lo sabe...

T.: ¿Él no ve lo que ocurre, lo que te hace su madre?

P.: Niega todo porque quiere y respeta a su madre... la relación que tienen es muy superficial, nunca tratan temas importantes, pero no puede dejar de mantener contacto con ella, le llama y visita permanentemente. Incluso cuando mi madre murió a los dos días estuvo toda la tarde en casa de su madre, ni pensó en cómo estaba yo.

T.: ¿No le pediste que se quedase?

P.: No, se lo dije al volver y me contestó: ¡Cómo no me has dicho nada!... Mi suegra ni me llamó cuando murió mi madre, pero le dijo a su hijo cuánto lo sentía: “¡Ves como si lo siente!”, me dijo, "exageras todo con mi madre".

T.: ¿Las discusiones suelen ser de este modo?

P.: Todas las discusiones acaban conmigo enfadada, no le hablo en dos o tres días y al cabo de ese tiempo me da pena verlo tan triste y me acerco y vuelvo a hablarle, entonces todo sigue como si nada hubiera pasado.

T.: ¿Y él, qué hace?

P.: Nada, él aguanta muy bien el silencio, siempre es así, desde hace muchos años. Al final siempre me entra la duda de si seré exagerada, de si me equivoco como él me dice. Al final acabo creyéndolo... ipor algo lo dirá!, pienso.

T.: Sorprende cómo tú misma lo dices tan convencida, cuando tú misma te encargas de ofrecer datos que te dan la razón.

P.: Pues lo he creído siempre...

T.: De todos modos, sigo perplejo ante la reacción terrible que has tenido, casi te matas.

P.: Puede que no se vea desde fuera, pero no podía más. No te he contado muchas cosas.

T.: Venga, es el momento, dímelas.

Me cuenta entonces problemas que ha tenido con un hermano de su marido por problemas de herencia y deslealtad en la gerencia de la empresa familiar.

P.: Me parecía muy injusto y se lo recriminé. Su reacción fue terrible, me insultó, me dijo que quería meterme en los asuntos familiares, atacarles... Cuando se enteró mi marido preparó una reunión con una propuesta para distribuir equitativamente el dinero, pero allí al final no hizo nada de lo que pensaba y aceptó lo ocurrido. Sin defenderme de lo sucedido. Me dijo, como siempre, que él lo resolvería, que no me metiese. El otro hermano es copartícipe de la empresa familiar, lleva años llevándose los mejores contratos, quedándose con los mejores clientes, eso nos ha costado mucho dinero, y cuando nos vemos todo son abrazos. Un día me enfadé y me prohibió que volviese a meterme en eso.

T.: ¿Quieres decir que tu marido te ha anulado?

P.: En casa de su familia sí, en el resto de temas te aseguro que no, sigo siendo la mujer que he sido. 
T.: ¿Qué haces con tu sentimiento de frustración, con tu rabia?

P.: Paso noches sin dormir, pero cuando empiezo a darle vuelta a las cosas acabo creyendo que tiene razón, que no debo meterme, que mi forma de ver las cosas no es buena, que soy una exagerada.

T.: ¿Y luego?

P.: Se me va pasando...

T.: ¿Así de fácil?

P.: No es tan sencillo, pero le veo en el salón después de las discusiones con esa "cara de cordero degollado" y me da mucha pena... Es algo raro, cuando se va pasando el enfado entro en un estado de confusión, empiezan las dudas, en la cabeza empiezo a pensar que por algo lo dirá, que quizá no tenga razón y me siento culpable, en la cama doy vueltas y pienso que no tengo razón.

T.: ¿Todo esto no ha afectado tu modo de mirarle, de relacionarte con él?

P.: ¡No!, él es una víctima (silencio)... Te voy a decir una cosa, la realidad es que estoy convencida de que él es perfecto, luego tengo que ser yo la equivocada. Me dice que su madre no es soberbia como yo digo, que es otra forma de ser, otra forma de querer diferente a la que yo tengo en mi familia. Me confunde y acabo aceptándolo...

T.: Nunca del todo.

P.: Eso es verdad, nunca del todo.

Valga esta secuencia para entender cómo ha sido su modo de sentir y enfrentar la situación todos estos últimos años. El modo en que su mente colonizada ha ido operando en la realidad.

Creo que el desmantelamiento del relato introyectado va avanzando. En la secuencia que viene ahora, unos meses después, los cuestionamientos se empiezan a hacer más evidentes. En estos momentos más avanzados del tratamiento busco que los modos de intervención sean más activos. Trato de que los diálogos se basen en situaciones o recuerdos muy emocionalmente vividos y aprovechar el "estado de labilidad" (Nadel y Land, 2000; Nader, Schafe y LeDoux, 2000; Sara, 2000) en que entra la memoria emocionalmente evocada en el vínculo terapéutico, para ayudar al cambio de las inscripciones antiguas (Bleichmar, 2001; de Gauna, Roibal, Ruiz, Fernández y Bleichmar, 2015*). Como se refiere en las citas mencionadas, para este trabajo se pueden utilizar diversos instrumentos que nos aproximen a lo vivencial: fotos, escritos, etc., en este caso planteo una especie de pequeña dramatización o role playing.

T.: Me has dado pruebas de tu capacidad para resolver problemas, para pelear negociaciones... ¿Cómo entiendes tu inhibición en esto?

P.: Yo no he intervenido porque él no me deja. Me ha prohibido que vaya a hablar con sus hermanos.

T.: ¿No te deja?

P.: Me lo ha prohibido, directamente me ha dicho qué no me deja que hable con su hermano. Si me hubiera permitido intervenir...

T.: Ese pareciera un razonamiento de mujer de otro siglo, a la que su marido le prohibía viajar o abrir una cuenta en el banco.

P.: (Sonríe) ¡Yo no soy esa mujer!, pero tampoco él es ese tipo de hombre. Pasa sólo en lo de su familia. Siempre hemos tenido una relación igualitaria con el dinero, con las decisiones importantes sobre nosotros o nuestros hijos, con nuestras opiniones políticas o sociales. Incluso puedo decir que él suele dejarse guiar por mis opiniones.

T.: ¿Alguna vez te has planteado porqué pasa esto?

P.: Ya te he dicho que me da pena y que acabo pensando que es mi culpa.

T.: Me parece que son cosas distintas, uno puede cambiar de opinión por pena, por no herir y otra cosa es que uno se lo crea.

P.: Te escucho y sé que es así, pero ¡cómo me va a tomar su familia en cuenta, si él no lo hace!

T.: Te propongo un juego, imagina que lo que estoy oyendo yo, lo estás oyendo tú de una amiga... ¿Puedes pensar en alguna a la que le haya pasado algo de este estilo?

P.: Sí he vivido situaciones con amigas que han tenido problemas de este tipo.

T.: A esa amiga le pasan las cosas que tú me cuentas... ¿qué le dirías?

P.: Te lo digo en un segundo, le diría que es imbécil, no tengo ninguna duda, que no puede tolerarlo, ni 
puede ni debe. [Me sorprendo y ella lo ve]. ¡Sí!, lo sé... pero yo no puedo hacerlo.

T.: ¿Qué le aconsejarías hacer a esa amiga?

P.: Que no lo tolerase, que se fuese, que se separase... [De nuevo me sorprendo y ella lo ve]. Pero yo no puedo, no puedo vivir sin él, me moriría. Nunca ni con la imaginación he pensado en separarme.

T.: Eso es lo que te ha puesto en una situación imposible y te ha llevado a intentar matarte: ni puedes soportarlo, ni puedes separarte.

P.: Tenemos broncas fenomenales, paso días sin hablarle, sin dormir, pero ni tan siquiera puedo insultarle en las discusiones, no me sale, jél es la primera víctima! Sólo de pensarlo me muero...

T.: Disculpa mi humor negro, pero eso dicho por una aprendiz de suicida resulta chocante.

P.: No es que todo sea chocante, es que no tiene sentido, pero no sé cómo explicártelo, es algo que noto muy hondo.

T.: Lo que quiero decir es que tu intento de matarte tenía mucha lógica. Me has hablado de lo que hiciste como una estupidez, como algo que no volverás a repetir. Pero si lo piensas era la única salida a esta situación: no podías aguantar más, ni podías separarte. Es como esos juegos de lógica que nos ponían cuando niños, en los que ninguna salida era aparentemente posible.

P.: Aquel día fue la gota que colmó el vaso. Sin pensarlo como lo estoy haciendo ahora, pero sé que sentí que no había nada que hacer, que lo mejor era desaparecer. Lo mejor para todos, si era un grano en el culo para él mejor desaparecer y mejor para todos.

T.: Bueno, tengo mis dudas de que fuese lo mejor para los que te rodean, pero desde luego para ti no era una buena solución.

P.: ¡Eso qué más da!, yo estaba convencida de que así paraba mi sufrimiento.

T.: Y esa amiga que nos hemos buscado, resulta que te enteras de que como su marido no interviene con su familia, decide suicidarse...

P.: Le diría que es la más tonta del mundo, pero yo ni quiero ni puedo vivir sin él.

T.: Ya sé que esto que te voy a decir no tiene mucho valor así dicho, pero es cierto: utilizas dos varas de medir. Y tú te llevas la peor, la más dura.

Tercera fase del tratamiento: Consolidación del nuevo relato mediante la relativización del viejo (la búsqueda de los orígenes). Al cabo de un año aproximadamente de tratamiento tanto las modificaciones vinculares entre nosotros como su propio discurso van cambiando. Entramos en otra fase del tratamiento, si denominamos a la anterior desmantelamiento del relato introyectado, ahora encontramos una continuidad en lo que podemos definir como la relativización del discurso. Con ello, al modo en que se plantea desde el enfoque modular-transformacional el trabajo sobre la modificación de las "creencias matrices pasionales" desde el modelo intersubjetivo (Méndez Ruiz e Ingelmo Fernández, 2011), queremos ayudar al paciente a que pueda sentir que la visión que tiene de la realidad, de los otros y de sí mismo no es algo que hay que tratar como una verdad absoluta, si no que se trata de una construcción con un origen y que, como tal, bien podría haber sido otra. Que son códigos subjetivos que dependen de los deseos y necesidades individuales y, como ocurre en este caso, de la forma en que se ha ido construyendo la interacción de la pareja.

En este momento del tratamiento, la paciente viene con ganas a las sesiones. Valora mucho poder hablar abiertamente de todo lo que le ocurre y siente que ello le hace bien. Creo que se ha sorprendido ante sí misma de poder hablar con libertad del tema. Mis intervenciones pasan a ser más confrontativas, buscando que observe sus contradicciones y sentimientos disociados. En esta fase pongo el foco en la búsqueda de los orígenes de la relación de pareja noto que va aumentando el nivel de rabia hacia la situación y hacia su marido. De todos modos es más evidente para mí que para ella porque el mecanismo disociativo de sus sentimientos sigue siendo muy potente.

Pasa por momentos de angustia, especialmente cuando recuerda los episodios de enfrentamiento con su marido, pero no puede ocultar la satisfacción que va sintiendo. Noto que la convicción en su relato de colonizada es algo menor.

P.: Esto es una revolución para mí... poder hablarlo... siempre he sentido que no merecía la pena, que la vida me ha dado más de lo que merezco. 
T.: Luego tu marido también es más de lo que mereces.

P.: Cuando vi que se interesaba en mí pensé: ¡Qué suerte!, me parecía imposible...

T.: ¿Por qué no me cuentas cómo se inició vuestra relación?

P.: Nos conocimos en un bar. Una amiga y su novio me llevaron para que lo conociese. Yo en esa época empezaba mi carrera.

T.: ¿Cómo te recuerdas en aquel momento?

P.: Era ingenua, feliz...

T.: ¿Así te definirías, te encontrabas bien contigo, con tu vida?

P.: Mi vida era feliz, pero yo estaba llena de miedos. Miedo a todo porque no sabía nada de la vida. La sexualidad era un tabú completo.

T.: ¿Por qué?

P.: Supongo que me los había metido mi madre... me veía a mí misma con cariño, creía en mis posibilidades. Yo siempre me he pensado como una mujer que triunfaría profesionalmente. Me relacionaba muy bien con la gente.

T.: ¿Y entonces el miedo del que hablas?

P.: Siempre he tenido mucho complejo con mi cuerpo. Me he considerado la más fea de mis hermanas. Desde pequeña. Me daban mucha vergüenza los chicos.

T.: Entonces esa chica con esas ideas sobre sí misma se presentó en el bar del que me hablas...

P.: Sí, me gustó desde el momento en que lo vi, me impresionó su conversación, su modo de vida, su aspecto. Para mi gran sorpresa me pidió el teléfono. No lo podía creer. Me llamó a la semana y así poco a poco...

T.: ¿Cómo fueron los inicios de la relación?

P.: Vivía pendiente de que me llamase. Corría al teléfono cada vez que sonaba. En tres meses me declaré, él tardó tres años.

T.: Fíjate que la relación la describes muy desigual desde el inicio.

P.: Contártelo así de seguido, me impresiona un poco. Porque recuerdo que pasaba noches enteras sin dormir, llorando...

T.: ¿Por qué?

P.: Porque no sabía si al día siguiente me iba a llamar. Nunca hubo enamoramiento loco por su parte.

T.: ¿Cuánto duró esta situación?

P.: Cinco años, hasta que nos casamos.

T.: ¿Cómo se comportaba contigo en ese tiempo?

P.: No sé decirte. Se portaba bien, no puedo decir otra cosa, viajábamos, nos veíamos como otras parejas, pero nunca me dijo que me quería o hablaba del futuro de nuestra relación.

T.: ¿Nunca preguntaste?

P.: Algunas veces y él me decía: “estás tonta, te quiero mucho”, pero para mí era imposible de creer, tengo la creencia de que no lo merezco. Me sigue asombrando.

Van surgiendo grietas en su antiguo relato.

P.: Me he dejado pisotear.

T.: ¿Por qué?

P.: Siempre me he dejado pisotear por su familia porque enfrentarme le hubiera hecho sufrir.

T.: Es como si su sufrimiento fuese más importante que el tuyo, ¿qué miedos podrían llevarte a ello?

P.: Supongo que esto que estamos hablando sobre la falta de cariño me tiene que influir...

T.: Seguramente, pero yo me refería a otros temores que pudieras sentir

P.: Yo tenía mucho miedo.

T.: Dices que a que él sufriera, pero pensemos en esos años de noviazgo que describes con tanto sufrimiento, cuando te oía me preguntaba cómo nunca pediste una explicación, un compromiso, o comentaste tu sufrimiento.

P.: Estos días estoy pensando que esos años me hicieron mucho daño. Acumulé mucha inseguridad que quizá ha condicionado toda la relación. 
T.: ¿De qué manera?

P.: Es como una especie de pecado original que luego lo ha llenado todo.

T.: Imagina ahora, en este momento estamos en aquel bar, una de aquellas tardes. De repente reúnes el valor de preguntarle... pregúntaselo ahora... ¿Qué respondería?

P.: (Silencio)... Me diría que no seguía conmigo. Creo que si me hubiera plantado se hubiera roto la relación.

T.: Luego no es sólo el temor a que sufra, es tu temor a perderlo.

P.: (Llora).

Cuarta fase del tratamiento: las motivaciones inconscientes del colonizador. Como señalábamos antes, en el proceso intersubjetivo que supone la relación colonizador/colonizado se ponen en juego las motivaciones conscientes y, especialmente, inconscientes de ambos. Por ello, considero llegado el momento de avanzar en el cambio de relato aproximándonos a las motivaciones inconscientes de su marido (el colonizador) e introducir así en el tratamiento la figura del colonizador para entender de modo vivencial que lo que está ocurriendo es un producto de la interacción entre ambos. En este caso, además, permite ver cómo el colonizador puede llegar a ser colonizado en otros vínculos. Es un modo de hacer comprender a la paciente lo subjetivo, lo relativo y cambiante que puede llegar a ser el proceso.

P.: El otro día estábamos leyendo después de la cena. Lo miraba y sentía que lo quería menos... otro día, discutimos por el cumpleaños de su madre, que viene ahora. No me llevó la contraria, pero se sentó en un sillón y empezó a poner la carita de pena. Le pude decir "no me culpabilices", pero enseguida me vine abajo y le dije "no te preocupes, ya lo arreglaremos, ya sé que soy demasiado estricta".

T.: ¡Qué secuencia!, te atreves a algo nuevo e inmediatamente te asustas. Supongo que no es fácil dejar de sentir lo que has sentido siempre. Creo que te aterroriza la posibilidad del abandono.

P.: Sí, me asusté, pero quizá sea hora de que él lo pase mal un rato con la cantidad de noches que yo he pasado llorando... además me dice que me quiere, que son cosas mías.

T.: Es importante que le quieran a uno, pero merece la pena pensar en el cómo te quieren. Pensemos en ello. ¿Cómo te quiere tu marido?

P.: No me lo he preguntado mucho... [Insisto]... Por ejemplo, ahora se me viene a la cabeza que él me quiere, pero parte del problema con su familia es que sus hermanos no saben lo importante que soy para él porque no lo dice. En mi casa todos le adoran porque yo siempre he hablado bien de él. Es como si me quisiera a escondidas.

Un día llega a una sesión y me dice que ha discutido con su marido, pero que ha sido diferente a otras veces.

P.: Quizá por lo que estábamos hablando aquí le dije que era muy cobarde con su familia, algo en mi tono le debió parecer diferente porque me dijo que era cierto, que siempre ha tenido miedo a que se rompiese su familia, que había sido un cobarde todo este tiempo como yo decía. No sé qué sentí en ese momento, pero me asusté y le grité sin pensar: “¡no es verdad, no eres cobarde!”.

T.: ¿De qué te asustaste tanto?, él reconoció lo que tú llevas tanto tiempo diciéndole.

P.: No lo sé, me entró susto.

T.: ¿Susto de qué? Te veo ahora muy tensa. Piensa que está pasando ahora, ¿qué sientes?

P.: Que no es por cobarde, que quizá es porque no le importa mucho que me agredan. ¿No te parece que puede ser?

T.: No me lo parece. Me dijiste que tu suegra trataba mal a vuestros hijos: ¿No le importa que agredan a sus hijos? ¿Pensamos entonces que no les importan sus hijos?

P.: ¡No, él adora a sus hijos!

T.: Bien, en ese caso tenemos que pensar en cobardía, pero una cobardía muy concreta que es enfrentarse a su familia.

P.: (Silencio).

T.: Pero decir cobardía no explica mucho. Yo estaba pensando en qué motivaciones puede tener él para mostrarse de ese modo. 
P.: Es como si tuviese que cumplir una misión.

T.: Ya que me preguntabas antes, algo así he pensado yo. Es como si tuviera un mandato que cumplir. Algo así como el deber de mantener unida su familia pase lo que pase.

En la siguiente sesión me dice:

P.: Estuve pensando mucho lo que hablamos. Recordé muchas cosas que he visto en mi marido en estos años. Si me olvido de la rabia que me causa cómo me trata, lo que pienso es que ha pasado mucho de su tiempo ocupado en cosas de su familia [Me cuenta muchas anécdotas de dedicación en temas afectivos, financieros, etc.].

T.: Oyéndote, pienso que tu marido tiene una especie de mandato de cuidado en el mantenimiento de su familia.

En una sesión posterior:

P.: Conseguí hablar tranquila con él, le pregunté sobre esto que venimos hablando y me dijo que él era el mayor, que su obligación era mediar entre sus hermanos, cuidar a su madre, me contó muchas cosas de esto, también que le habían dicho desde pequeño que tenía que dar ejemplo. Me pasaba como seguramente te pasa a ti conmigo, le oía y me preguntaba cómo es posible que no se dé cuenta de las consecuencias de lo que está haciendo... al final me dijo, por eso quiero ocuparme de las cosas de mi casa yo mismo.

T.: Te quiero proponer una cosa. Por supuesto que si no te parece bien o no es el momento me lo puedes decir... ¿Por qué no aprovechas que ahora estáis hablando de otra manera y le preguntas sobre aquellos primeros años de la relación? Preguntarle por cómo se sintió él.

Unos días más tarde me cuenta lo siguiente:

P.: Estuve hablando con él, le recordé lo que pasó esos años. Bueno, tendré que decir, lo que pasé yo, porque él me dijo que no recordaba nada de aquello que le decía. Que le cuesta mostrar los afectos, pero que no sabía que yo lo había pasado tan mal. Me dijo: “¡Estoy contigo! ¿No?, además estos años hemos estado muy bien juntos, así que ya ves que no te he engañado o que no jugué esos años contigo". ¿Qué te parece?...

T.: No sé qué pensar. Por un lado, me cuesta pensar que él no vio nada de tu sufrimiento. Aunque hay personas muy incapaces para eso. Por otro lado, tú no dijiste nada. Qué se yo, a lo mejor no fue tan evidente lo que te pasaba. Tú puedes llegar a camuflar mucho tus sentimientos, incluso ante ti misma.

\section{Comentario final y conclusiones}

Expongo en este trabajo una primera parte del tratamiento que nos ha llevado algo más de un año y medio con una frecuencia de dos sesiones semanales (salvo las primeras semanas, en las que el riesgo autolítico exigió mayor frecuencia). Se trata de una primera fase del tratamiento centrada en los efectos que ha tenido sobre ella la relación con su marido. Es una opción de estrategia terapéutica para intervenir sobre aspectos centrales de su problemática actual. La idea es, como comentaré más adelante, dejar para un segundo momento el análisis de los códigos y las creencias con los que ella entra en la relación.

Al final de ese tiempo se han producido cambios muy significativos: han desaparecido las ideas autolíticas y, lo que es más importante, buena parte de la fuerza consciente e inconsciente que las impulsaba y las mantenía. Por otra parte, la fuerza de la disociación, imprescindible para mantener la condición de colonizada que, en cierto modo, no es más que estar atrapada en la aceptación emocional acrítica del discurso del otro, ha ido disminuyendo. Esto se ha producido porque la construcción de un vínculo seguro ha permitido poner en palabras, explicitar, ideas y sentimientos que permanecían reprimidas o implícitas. Esto, en sí mismo, ha favorecido la disminución de la disociación. Además, porque se ha buscado el desmantelamiento de un relato que la paciente ha ido introyectando a lo largo de su vida de pareja sin crítica alguna. Ayudarle a entender que dicho relato no es único, que pudieron darse otros si las circunstancias personales y relacionales hubieran sido diferentes es terapéutico porque siempre que los relatos y los mandatos, sean del tipo que sean, pueden relativizarse, pierden una parte de su poder. En este sentido, la búsqueda de los orígenes del relato es un paso de importancia porque siempre que comprendemos, racional 
y emocionalmente, que algo nació en un tiempo y una situación concreta pierde la fuerza que da el pensar en algo eterno e inmutable.

Por supuesto, cabe pensar que las modificaciones que se han producido estén condicionadas por el influjo de la relación terapéutica, a modo de un proceso sugestivo. Esto indudablemente ha tenido su peso en este proceso terapéutico, como ocurre en cualquiera y especialmente en sus primeras fases, ya sea en forma intencionada al utilizar la sugestión como técnica terapéutica, que no es el caso, o en el desarrollo del vínculo transferencial, pero considero que se han ido produciendo cambios en la estructura psíquica de la paciente: en sus modos de sentir, en sus modos de actuar ante el propio sentir, así como en el modo de relacionarse intrapsíquicamente con sus propias motivaciones conscientes e inconscientes.

Sin embargo, sí es razonable pensar que estamos ante un proceso terapéutico inconcluso que sólo se consolidará cuando se pueda pasar a trabajar los condicionantes propios de la paciente, aquellos con los que se presenta al iniciar la relación con su marido. Habrá que abordar los propios relatos internos de la paciente, sus propios modos de encarar sus angustias o sus motivaciones inconscientes, ya que la desvalorización que la familia del marido ha hecho de ella se consolida de modo tan sólido, no sólo por la conducta del marido, sino por un código y una imagen desvalorizada de sí misma que es previa a los intercambios con él y que permite que esos códigos entren con tal intensidad y se instalen en su psiquismo. Por ello, es importante señalar que las respuestas de la paciente no pueden estar determinadas solo por el exterior, resulta evidente que no toda persona que siente que no se le quiere o no se le valora aguanta dicha situación durante décadas y al final pone en marcha un intento autolítico. Podríamos decir que existe un autolavado de cerebro previo a la relación con su marido. Sólo el trabajo sobre su historia familiar, sus identificaciones, su relación con el sentimiento de culpa, sus fallas narcisistas previas a la relación con su marido, etc. pueden liberarla de estas ataduras emocionales. Esa debe ser la continuación en este proceso terapéutico. Seguimos trabajando.

\section{Referencias}

Blass, R. B. (junio, 2013). La conceptualización de la escisión. Acerca de los distintos significados de la escisión y sus implicaciones para la comprensión de la persona y el proceso psicoanalítico. Aperturas psicoanalíticas, 44. Recuperado de http://www.aperturas.org/articulos.php?id=0000819\&a=La-conceptualizacion-de-la-escision-Acerca-de-los-distintos-significados-de-la-escision-y-sus-implicaciones-para-la-comprension-de-la-persona-y-el-proceso-analitico

Bleichmar, H. (1997). Avances en psicoterapia psicoanalítica. Hacia una técnica de intervenciones específicas. Barcelona, España: Paidós Ibérica.

Bleichmar, H. (noviembre, 2001) El cambio terapéutico a la luz de los conocimientos actuales sobre la memoria y los múltiples procesamientos inconscientes. Aperturas Psicoanalíticas, 9. Recuperado de http://www. aperturas.org/articulos.php?id=178\&a=El-cambio-terapeutico-a-la-luz-de-los-conocimientos-actuales-sobre-la-memoria-y-los-multiples-procesamientos-inconscientes

Bleichmar, H. y Espeleta, S. (enero, 2017). Teoría y técnica de la descolonización emocional: una introducción. Aperturas psicoanalíticas, 54. Recuperado de http://www.aperturas.org/articulos.php?id=962\&a=Teoria-y-tecnica-de-la-descolonizacion-emocional-una-introduccion

The Boston Change Process Study Group (2010). Change in Psychotherapy. A unifying paradigm. Nueva York, Estados Unidos: W.W. Norton \& Company.

de Gauna M. I., Roibal, M. A., Ruiz, J. A., Fernández J. I., Bleichmar H. B. (2015). Active change in psychodynamic therapy: moments of high receptiveness. The American Journal of Psychotherapy, 69(1), 65-86.*

Méndez Ruiz, J. A. e Ingelmo Fernández, J. (2009). La psicoterapia psicoanalítica desde la perspectiva del enfoque Modular-Transformacional. Introducción a la obra de Hugo Bleichmar. Madrid, España: Sociedad Forum de Psicoterapia Psicoanalítica.

Méndez Ruiz, J. A. e Ingelmo Fernández, J. (diciembre, 2011). Las Creencias Matrices Pasionales desde la perspectiva de la intersubjetividad. Aperturas psicoanalíticas, 39. Recuperado de http://www.aperturas.org/ 
articulos.php?id=731\&a=Las-creencias-matrices-pasionales-desde-la-perspectiva-de-la-intersubjetividad

Nadel, L. y Land, C. (2000). Memory traces revisited. Nature Reviews: Neuroscience, 1, 209-212.

Nader, K., Schafe, G. E. y LeDoux, J. E. (2000). The labile nature of consolidation theory. Nature, Reviews: Neuroscience, 1(3), 216-219.

Pichon-Rivière, E. (1981). El proceso grupal. Buenos Aires, Argentina: Ediciones Nueva Visión. (Original publicado en 1971).

Sara, S. J. (2000). Strengthening the shaky trace through retrieval. Nature Review: Neuroscience, 1, 212-213.

Artículo recibido: 10/01/2018

Revisión recibida: 06/12/2018

Artículo aceptado: 09/02/2018

* Es necesario aclarar que, por error de la revista donde originalmente se publicó esta fuente, los apellidos de tres de los autores han sido trastocados, por lo que no se reconocen. Uno de los coautores, que aparece como "Ruiz", corresponde precisamente al autor del presente artículo, José Antonio Méndez Ruiz. El segundo coautor, “de Gauna”, es en realidad Mariano de Iceta de Gauna . El tercer coautor, "Fernández" debería aparecer como Joaquín Ingelmo Fernández. 